\title{
Transcobalamin II in Human Seminal Plasma
}

Ralph Carmel and Gerald S. Bernstein

Departments of Medicine and Obstetrics and Gynecology, University of Southern California School of Medicine, and the Los Angeles County-University of Southern California Medical Center, Los Angeles, California 90033

bstract. Study of cobalamin-binding proteins revealed seminal plasma to be the most concentrated site of transcobalamin II in man. The next richest normal fluid, blood, has approximately one-tenth its concentration. Normal seminal unsaturated cobalamin-binding capacity averaged $15,030 \pm 7,290 \mathrm{pg} / \mathrm{ml}$, of which $11,550 \pm 6,660 \mathrm{pg} / \mathrm{ml}$ was transcobalamin II. Transcobalamin II levels were markedly diminished in subjects lacking seminal vesicles (1520-1660 pg/ml), but not after vasectomy. This suggests that seminal vesicles are the chief source of this protein in semen. $R$ binder concentration was increased in postvasectomy subjects $(9,970 \pm 4,900 \mathrm{pg} / \mathrm{ml}$ vs. $2,980 \pm 1,370 \mathrm{pg} / \mathrm{ml}$ in normals) and varied in other patients. The endogenous cobalamin content of semen was only $88-699 \mathrm{pg} / \mathrm{ml}$, and was carried largely by $R$ binder rather than by transcobalamin II. The function of the unusually large seminal transcobalamin II pool in reproduction is unknown, but seems unlikely to be related solely to cobalamin transport needs, at least within the male reproductive tract itself.

\section{Introduction}

Clinical observations have implicated cobalamin (vitamin $\mathbf{B}_{12}$ ) as an important nutrient for maintaining normal fertility in both sexes (1-5). However, little is known about its status or transport in the reproductive tract. Indeed, despite the considerable information that has accumulated about the composition of human seminal plasma (6), relatively little is available about this fluid's multitude of trace proteins (7) or the status of its

Address all correspondence to Dr. Carmel, University of Southern California School of Medicine, Los Angeles, CA 90033.

Received for publication 17 August 1983 and in revised form 24 October 1983.

J. Clin. Invest.

(c) The American Society for Clinical Investigation, Inc. 0021-9738/84/03/0868/05 \$1.00

Volume 73, March 1984, 868-872 nutrient substances. Brief surveys, confining themselves to abnormal patients, found cobalamin levels in seminal plasma to range from barely detectable to approaching $600 \mathrm{pg} / \mathrm{ml}(8,9)$. Nothing is known about cobalamin transport, an intricate system elsewhere in the body, other than the immunological identification of both $\mathrm{R}$ binder ${ }^{1}$ and transcobalamin II in normal semen (10). Therefore, we undertook to examine these binding proteins and establish their normal distribution upon which to base further observations on normal and abnormal cobalamin transport in reproduction. We report here our results which show that semen is surprisingly rich in transcobalamin II. The findings also indicate that variations occur in the two major cobalaminbinding proteins, and raise the interesting possibility that these will ultimately prove useful in studying reproductive disorders.

\section{Methods}

Four groups of men provided semen: $(a)$ six healthy fertile men with normal semen who were regular donors for artificial insemination or our reproductive physiology laboratory; $(b)$ six men who had undergone vasectomy and whose semen no longer contained any spermatozoa; $(c)$ two infertility patients with congenital absence of the seminal vesicles and vasa deferentia (both had azoospermia, a low semen volume of $<1$ $\mathrm{ml}$, a semen $\mathrm{pH}$ below 7.0, and absence of seminal fructose; the diagnosis of absent vasa deferentia was confirmed by surgical exploration of the scrotum); and $(d)$ two infertility patients with oligozoospermia. One of the last two patients had sperm counts of $10 \times 10^{6} / \mathrm{ml}$ or less in five of seven analyses, a low follicle-stimulating hormone level, and urethritis associated with Ureaplasma urealyticum. The other patient had sperm counts $<10^{6} / \mathrm{ml}$, had undergone vasovasostomy after an earlier vasectomy, had a history of nongonococcal urethritis and epididymitis, and had sperm-immobilizing antibody in his blood.

Semen was collected into jars by masturbation. Seminal plasma was obtained by centrifugation. A double-centrifugation process, wherein an

1. $\mathbf{R}$ binders comprise an immunologically homogeneous but isoelectrically heterogeneous family of cobalamin-binding glycoproteins that are present in all human secretions and in many cells (see Reference 17 for review). An example is transcobalamin I in serum, though secretions like saliva and tears are much richer in $\mathbf{R}$ binder than is serum. The function of $R$ binders is not known, in contrast to the crucial function of the unrelated transcobalamin II in promoting cellular uptake of cobalamin. 
initial spin at $250 \mathrm{~g}$ for $10 \mathrm{~min}$ was followed by one at $2000 \mathrm{~g}$ for 20 min, was used in most cases but not all. However, the exact conditions of centrifugation did not appear to be crucial for our purposes. In three normal cases, the plasma contained $24-62 \times 10^{6}$ spermatozoa $/ \mathrm{ml}$ after the first centrifugation and $0.33-0.46 \times 10^{6}$ spermatozoa/ml after the second; despite such differences, the two supernates in each case differed by $<10 \%$ from each other in their cobalamin-binding protein quantities and profiles. Omission of the first spin in a fourth case produced results similar to those by double centrifugation of a second aliquot.

Specimens were studied either immediately or after storage at $-20^{\circ} \mathrm{C}$ in polypropylene tubes. Examination of two normal and two abnormal seminal fluids confirmed that the cobalamin-binding proteins remained stable even after 3 -mo storage at $-20^{\circ} \mathrm{C}$.

Quantitation of unsaturated cobalamin-binding capacity and its fractionation into its binder components was done by column chromatography of 10 or $20 \mu$ aliquots of seminal plasma that had been incubated for $1 \mathrm{~h}$ at room temperature with an amount of ${ }^{57} \mathrm{Co}$-labeled cyanocobalamin (10-15 $\mu \mathrm{Ci} / \mu \mathrm{g}$ sp act; Amersham/Searle Corp., Arlington Heights, IL) exceeding its binding capacity. The Sephadex G200 gel filtration was performed with $0.1 \mathrm{M}$ Tris-1 $\mathrm{M} \mathrm{NaCl}$ buffer, $\mathrm{pH}$ 8.6. The individual cobalamin-binding proteins were also characterized with specific anti-R binder and anti-transcobalamin II antisera as before (11). Cobalamin content was measured by radioassay using $\mathbf{R}$ binder (12). Distribution of the endogenous cobalamin among the binding proteins in seminal plasma was determined by radioassay of eluate fractions obtained by Sephadex gel chromatography (13).

\section{Results}

All seminal plasma specimens contained much higher unsaturated cobalamin-binding capacity than does normal serum (in our laboratory, normal mean \pm 1 SD among 38 normal sera was $1,341 \mathrm{pg} / \mathrm{ml} \pm 297)$. The levels remained relatively constant in semen samples collected on different days. Three specimens obtained from normal subject 1 over 2 mo did not vary by $>25 \%$ in any binding parameter (data not shown).

Seminal plasma contained large amounts of both $\mathrm{R}$ binder and transcobalamin II, as shown by gel chromatography (Fig. 1). All 16 subjects except postvasectomy subject 2 had detectable amounts of cobalamin binder eluting with the void-volume fraction also. However, the small amounts and the proximity of the void-volume peaks to the much greater $\mathrm{R}$ binder peaks on chromatography made quantitation of this poorly understood binder difficult. The two major binder peaks reacted completely with anti- $R$ binder and anti-transcobalamin II antisera, respectively, as shown by the resultant shift of these peaks to the void volume on rechromatography after incubation with each antiserum.

Table I lists the extremely high cobalamin-binding capacity levels found in semen. Though the range was very wide, binding capacities did not differ between normal and abnormal specimens ( $\mathrm{t}=0.564$ for normal vs. postvasectomy subjects) by Student's $t$ test. Transcobalamin II constituted most of the binding protein in normal seminal plasma (Table I). However, this was not true in many abnormal specimens. In the fluids from patients with vasectomy, $\mathrm{R}$ binder levels were increased com-

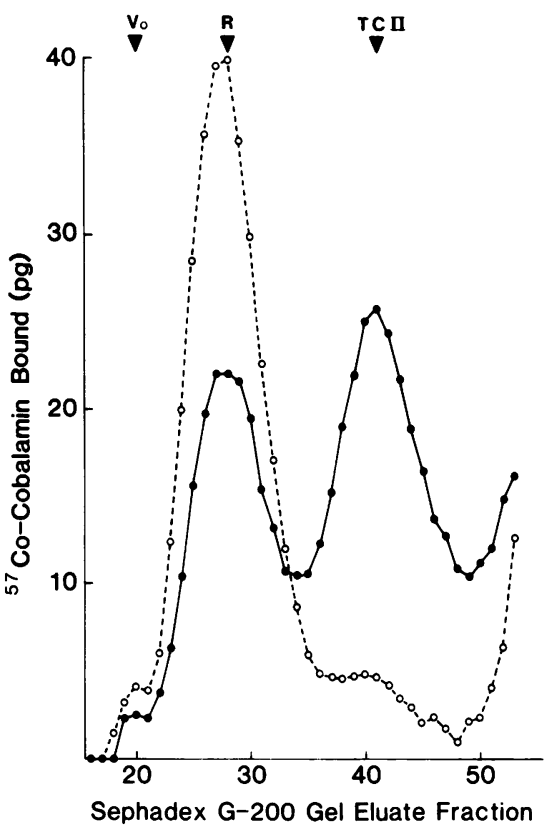

Figure 1. Fractionation of seminal plasma unsaturated cobalaminbinding capacity by Sephadex G-200 gel chromatography. ( $\bullet-\bullet)$, $0.02 \mathrm{ml}$ of seminal plasma from postvasectomy subject 6 ; its elution pattern resembles that of normal seminal plasma except that it has a much larger $\mathbf{R}$ binder component than normal. ( $0---0), 0.02 \mathrm{ml}$ of seminal plasma from subject 1 with congenital absence of seminal vesicles. $V_{0}$, void volume; $R, R$ binder elution position; TC II, transcobalamin II elution position.

pared with normal $(\mathrm{t}=3.369, P<0.01)$ while transcobalamin II remained normal $(\mathrm{t}=1.391)$. This resulted in $\mathrm{R}$ binder levels exceeding transcobalamin II levels in half the cases.

In contrast, the two subjects lacking seminal vesicles demonstrated sharply decreased transcobalamin II content. While transcobalamin II in normal seminal plasma $(11,550 \mathrm{pg} /$ $\mathrm{ml} \pm 6,660$ ) was on the average ten times higher than found in normal serum in our previous studies $(1,028 \mathrm{pg} / \mathrm{ml} \pm 225)$, subject 1 with absent seminal vesicles had a seminal transcobalamin II level only 1.5 times that in his simultaneously obtained serum $(1,123 \mathrm{pg} / \mathrm{ml})$. His seminal transcobalamin II, though reduced greatly in amount, was reactive with anti-transcobalamin II antibody. Incubating his seminal plasma with an equal volume of normal seminal plasma did not decrease the latter's transcobalamin II level, indicating that his semen did not contain an inhibitor or lytic factor. Virtually identical cobalamin-binding profiles were obtained in semen samples collected 4 mo apart in this patient (Table I).

Seminal cobalamin content was $88-226 \mathrm{pg} / \mathrm{ml}$ in three normal subjects, $362-699 \mathrm{pg} / \mathrm{ml}$ in four postvasectomy patients, and $332-488 \mathrm{pg} / \mathrm{ml}$ in the two patients with oligozoospermia. Insufficient volume prevented assay in the cases of absent seminal vesicles. A trend toward higher cobalamin concentrations among 
Table I. Unsaturated Cobalamin-binding Proteins in Seminal Plasma

\begin{tabular}{|c|c|c|c|c|}
\hline Subjects & Cobalamin-binding capacity* & $\mathbf{R}$ binder * & Transcobalamin $\mathrm{II}^{*}$ & $\begin{array}{l}\text { Transcobalamin II } \\
\text { (\% of binding capacity) }\end{array}$ \\
\hline \multicolumn{5}{|l|}{ Normal } \\
\hline 1 & 8,020 & 3,010 & 4,990 & 62 \\
\hline 2 & 8,900 & 2,100 & 6,600 & 74 \\
\hline 3 & 10,250 & 3,300 & 6,450 & 63 \\
\hline 4 & 19,650 & 5,000 & 14,100 & 72 \\
\hline 5 & 26,500 & 3,500 & 21,950 & 83 \\
\hline 6 & 16,850 & 950 & 15,200 & 90 \\
\hline Mean \pm SD & $15,030 \pm 7,290$ & $2,980 \pm 1,370$ & $11,550 \pm 6,660$ & $74 \pm 11$ \\
\hline \multicolumn{5}{|c|}{ Postvasectomy } \\
\hline 1 & 8,170 & 2,780 & 5,360 & 66 \\
\hline 2 & 12,410 & 8,950 & 3,460 & 28 \\
\hline 3 & 22,900 & 9,150 & 13,500 & 59 \\
\hline 4 & 21,630 & 17,790 & 3,780 & 17 \\
\hline 5 & 16,700 & 12,100 & 4,200 & 25 \\
\hline 6 & 21,300 & 9,050 & 11,750 & 55 \\
\hline Mean \pm SD & $17,190 \pm 5,890$ & $9,970 \pm 4,900$ & $7,010 \pm 4,430$ & $42 \pm 21$ \\
\hline \multicolumn{5}{|c|}{ Absent seminal vesicles } \\
\hline $1 \ddagger$ & 17,400 & 15,580 & 1,660 & 10 \\
\hline 2 & 5,660 & 4,020 & 1,520 & 27 \\
\hline Mean & 11,530 & 9,800 & 1,590 & 19 \\
\hline \multicolumn{5}{|c|}{$\begin{array}{l}\text { Miscellaneous } \\
\text { infertility cases }\end{array}$} \\
\hline 1 & 12,420 & 1,180 & 11,100 & 89 \\
\hline 2 & 12,060 & 620 & 11,380 & 94 \\
\hline
\end{tabular}

* The values are given in picograms per milliliter. They appear rounded off because they are derived from values obtained by assaying 10 or 20 $\mu l$ aliquots. (For the same reason, the mean and standard deviation have been rounded off also). The unsaturated cobalamin-binding capacity exceeds the sum of the unsaturated $R$ binder and transcobalamin II-binding capacities because it also includes minor binders, primarily the binder eluting chromatographically with the void-volume fraction, which are not given here. ‡ A 4-mo-old specimen previously collected from this patient had an unsaturated cobalamin-binding capacity of $18,450 \mathrm{pg} / \mathrm{ml}$, of which $9 \%$ was transcobalamin II.

the abnormal specimens thus appears from these limited data. Fractionation studies in three normal specimens revealed that $62-73 \%$ of the endogenous cobalamin in semen was attached to $\mathrm{R}$ binder and only $6-17 \%$ was carried by transcobalamin II; $16-32 \%$ was carried in the void-volume fraction.

\section{Discussion}

The strikingly higher concentration of transcobalamin II in seminal plasma, averaging tenfold that in serum, makes semen by far the most concentrated depot of transcobalamin II in man. The only other known sites are milk, whose mean transco- balamin II level of $870 \mathrm{pg} / \mathrm{ml}$ approximates that of serum (14); cerebrospinal fluid, whose mean level of $302 \mathrm{pg} / \mathrm{ml}$ (15) is less than one-third the concentration found in serum; and saliva, which was recently shown to contain $130-378 \mathrm{pg} / \mathrm{ml}$ in one abnormal subject (13). Synovial fluid in patients with arthritis had transcobalamin II levels slightly above those in the blood (16), but the levels in normal fluid are unknown. As reviewed elsewhere (17), all other secretions, such as gastric juice, amniotic fluid, bile, and tears, contain little or no transcobalamin II.

The amount of $\mathbf{R}$ binder that we found in seminal plasma was also very high. However, semen is not unique in this respect, since similar or higher $\mathbf{R}$ binder concentrations exist in most secretions (17). 
The prostate and seminal vesicles contribute the major portion of the seminal plasma volume, but whole semen contains constituents from other parts of the male reproductive tract as well (6). Evaluation of men with anatomical disorders thus provides some clues about the origin of the cobalamin-binding proteins in normal semen. Semen from normal volunteers should contain all components including spermatozoa. Samples from patients with vasectomy should have no contribution from the testis or epididymis. Semen from subjects without seminal vesicles and vasa deferentia should consist primarily of prostatic fluid and not contain any material from that portion of the tract proximal to the prostate.

The markedly reduced seminal transcobalamin II levels in men without seminal vesicles and vasa deferentia, and the normal levels in postvasectomy subjects implicate the seminal vesicles as the major source of transcobalamin II. One can not entirely rule out contribution from the other accessory glands, as they too may have been absent in the former subjects. Moreover, it should be noted that the transcobalamin II was greatly diminished but not absent, so that other sources, most likely prostate, must contribute small amounts. Wherever it occurs, the prolific elaboration and/or exudation within the male reproductive system demonstrates that important depots of transcobalamin II exist outside the blood stream. The possibility that various sources exist for transcobalamin II in man awaits more direct resolution, and is hampered by the fact that, despite various suggestive studies, the cellular origin of this binder remains unknown (17).

In contrast to transcobalamin II, $\mathrm{R}$ binder was not decreased in either group of anatomically abnormal patients. In fact, its concentration was increased in postvasectomy semen. Thus, spermatozoa can not be a major source of seminal $R$ binder. Why vasectomy should produce elevated seminal $R$ binder levels is unclear at present. It is interesting that our two infertile patients with oligozoospermia had low seminal $\mathrm{R}$ binder content; however, one healthy volunteer had similarly low levels. The information signaled by the various cobalamin-binding protein changes in reproductive disorders is a subject worthy of further exploration.

Seminal cobalamin concentration was of the same order of magnitude as that of serum, as noted by others $(8,9)$. Our data do not support previous suggestions that abnormal semen tends to have lower cobalamin content $(8,9)$. However, the comparison, selection, and nature of those subjects differed from ours. An additional contribution to the difference may be that those studies assayed cobalamin microbiologically whereas our radioassay using $\mathrm{R}$ binder detects analogues as well as "true" cobalamin. Study of larger numbers of subjects will be needed to resolve these issues.

The most intriguing question raised by our findings is why semen should be so rich in transcobalamin II. Such large amounts seem clearly excessive for vitamin transport needs, particularly in view of the relatively small cobalamin content in semen. Moreover, as in serum $(18,19)$ but not as in cerebrospinal fluid
(15), what cobalamin is present is carried largely by $R$ binder rather than by transcobalamin II. Indeed, less seminal cobalamin was carried by transcobalamin II than even by a poorly understood minor binder which eluted chromatographically in the void-volume fraction. The latter binder is regularly observed in serum (20-22), but there carries only a tiny fraction of the circulating cobalamin $(13,18)$. Finally, our data indicate that seminal transcobalamin II is largely delivered at an anatomical point distal to where spermatozoa would require cobalamin during their production and storage. Therefore, we suggest that the function of transcobalamin II is not related solely to its conventional cobalamin transport role, at least within the male reproductive tract itself. It may serve some additional purpose in the male. Alternatively, its cobalamin transport or other function may be important subsequently in the fertilization process after leaving the male reproductive tract.

\section{Acknowledgment}

We thank Rosemarie E. Nimo for technical assistance.

This study was supported in part by Biomedical Research Support grant 2 S07 RR05466-15 from the Department of Health and Human Services.

\section{References}

1. Adams, J. F. 1958. Pregnancy and Addisonian pernicious anaemia. Scott. Med. J. 3:21-25.

2. Sharp, A. A., and L. J. Witts. 1962. Seminal vitamin $B_{12}$ and sterility. Lancet. II:779.

3. Furnass, B. 1963. Seminal vitamin $B_{12}$ and sterility. Lancet. I:5960.

4. Jackson, I. M. D., W. B. Doig, and G. McDonald. 1967. Pernicious anaemia as a cause of infertility. Lancet. II:1159-1160.

5. Girdwood, R. H., M. A. Eastwood, N. D. C. Finlayson, and G. S. Graham. 1971. Pernicious anaemia as a cause of infertility in twins. Lancet. I:528-530.

6. Mann, T., and C. Lutwak-Mann. 1981. Male Reproductive Function and Semen. Springer-Verlag, Berlin, 269-336.

7. Edwards, J. J., S. L. Tollaksen, and N. G. Anderson. 1981. Proteins of human semen. I. Two-dimensional mapping of human seminal fluid. Clin. Chem. 27:1335-1340.

8. Watson, A. A. 1962. Seminal vitamin $B_{12}$ and sterility. Lancet. II:644.

9. Tomaszewski, L., B. Zmudzka, and J. Nadworny. 1963. Seminal vitamin $B_{12}$ and sterility. Lancet. I:170.

10. Finkler, A. E., P. D. Green, and C. A. Hall. 1970. Immunological properties of human vitamin $\mathrm{B}_{12}$ binders. Biochim. Biophys. Acta. 200:151-159.

11. Carmel, R., and L. Baril. 1978. Circulating immunoglobulintranscobalamin I (R binder) complexes. J. Lab. Clin. Med. 91:769-779.

12. Carmel, R., and C. A. Coltman, Jr. 1969. Radioassay for serum vitamin $\mathbf{B}_{12}$ with the use of saliva as a vitamin $\mathbf{B}_{12}$ binder. J. Lab. Clin. Med. 74:967-975. 
13. Carmel, R. 1982. A new case of deficiency of the $R$ binder for cobalamin, with observations on minor cobalamin-binding proteins in serum and saliva. Blood. 59:152-156.

14. Sandberg, D., J. A. Begley, and C. A. Hall. 1981. The content, binding and forms of vitamin $\mathrm{B}_{12}$ in milk. Am. J. Clin. Nutr. 34:17171724.

15. Lazar, G. S., and R. Carmel. 1981. Cobalamin binding and uptake in vitro in the human central nervous system. J. Lab. Clin. Med. 97:123-133.

16. Gullberg, R. 1972. Vitamin $B_{12}$-binding proteins in blood plasma and synovial fluid in arthritis. Scand. J. Rheumatol. 1:129-135.

17. Carmel, R. 1981. Cobalamin-binding proteins of man. In Contemporary Hematology/Oncology. R. M. Silber, A. S. Gordon, J. LoBue, and F. M. Muggia, editors. Plenum Publishing Corp., New York, 2:79129.
18. England, J. M., M. C. Down, I. J. Wise, and J. C. Linnell. 1976. The transport of endogenous vitamin $B_{12}$ in normal human serum. Clin. Sci. Mol. Med. 51:47-52.

19. Hall, C. A. 1977. The carriers of native vitamin $B_{12}$ in normal human serum. Clin. Sci. Mol. Med. 53:453-457.

20. Hom, B. L., and B. K. Ahluwalia. 1968. The vitamin $B_{12}$ binding capacity of transcobalamins I and II of normal human serum. Scand. J. Haematol. 5:64-74.

21. Natori, H. 1971. Physicochemical analyses of vitamin $B_{12}$ binding proteins in sera, gastric juice and leucocytes. Tumor Res. 6:1-79.

22. Carmel, R. 1979. Large vitamin $B_{12}$-binding proteins and complexes in human serum. In Vitamin $\mathbf{B}_{12}$. Proceedings of the Third European Symposium on Vitamin $B_{12}$ and Intrinsic Factor. B. Zagalak, and W. Friedrich, editors. Walter de Gruyter \& Co., Berlin, 777-790. 